\title{
Neutrophil Gelatinase-associated Lipocalin Significantly Correlates with Ischemic Damage in Patients Undergoing Laparoscopic Partial Nephrectomy
}

\author{
Meltem Savran Karadeniz1, Isbara Alp Enişte ${ }^{2}$, Hayriye Şentürk Çiftçi³, Sebahat Usta ${ }^{3}$, Tzevat Tefik ${ }^{4}$, \\ Öner Şanlı4, Kamil Pembeci1, Kamil Mehmet Tuğrul1
}
${ }^{1}$ Department of Anesthesiology, İstanbul University İstanbul School of Medicine, İstanbul, Turkey
${ }^{2}$ Clinic of Anesthesiology, Grup Florence Nightingale Hospital, İstanbul, Turkey
${ }_{3}^{3}$ Department of Medical Biology, İstanbul University İstanbul School of Medicine, İstanbul, Turkey
${ }^{4}$ Department of Urology, İstanbul University İstanbul School of Medicine, İstanbul, Turkey

\begin{abstract}
Background: Laparoscopic partial nephrectomy, which minimizes renal function loss due to its nephron sparing nature, has become a standard technique among many experienced centers worldwide for surgical treatment of localized kidney tumors. Although partial nephrectomy will remain the gold standard, we need to improve perioperative management and surgical method to prevent postoperative acute kidney injury.
\end{abstract}

Aims: To demonstrate the frequency of the development of postoperative acute kidney injury following laparoscopic partial nephrectomy in patients with healthy contralateral kidney and determine the early predictive effects of serum neutrophil gelatinaseassociated lipocalin on ischemia-reperfusion injury and its association with warm ischemia time.

Study Design: Cross-sectional study.

Methods: Eighty patients were included. We analyzed tumor size, operating time, duration of anesthesia, and warm ischemia time. Serum samples were obtained for measurement of serum creatinine, estimated glomerular filtration rate, and neutrophil gelatinaseassociated lipocalin level preoperatively, at the postoperative 2nd hour, and on postoperative days 1 and 2 . We used receiver operating characteristic curve for determining the cut-off point of neutrophil gelatinase-associated lipocalin to detect postoperative acute kidney injury. Correlation analysis was performed using Spearman's test.
Results: Twenty-seven patients developed acute kidney injury on postoperative day 2 , and the neutrophil gelatinase-associated lipocalin level increased significantly at the postoperative $2^{\text {nd }}$ hour in the acute kidney injury group ( $\mathrm{p}=0.048$ ). For a cut-off of $129.375 \mathrm{ng} /$ $\mathrm{mL}$ neutrophil gelatinase-associated lipocalin, the test showed $70.0 \%$ sensitivity and $68.3 \%$ specificity for the detection of acute kidney injury at the postoperative $2^{\text {nd }}$ hour. For a cut-off of $184.300 \mathrm{ng} / \mathrm{mL}$ neutrophil gelatinase-associated lipocalin, the test exhibited $73.3 \%$ sensitivity and $63.3 \%$ specificity for the detection of acute kidney injury on postoperative day 1 . A significant correlation was found between warm ischemia time and neutrophil gelatinase-associated lipocalin level at the postoperative $2^{\text {nd }}$ hour $(\mathrm{r}=0.398, \mathrm{p}=0.003)$. The creatinine values were significantly higher and the estimated glomerular filtration rates were significantly lower on postoperative days 1 and 2 in the acute kidney injury group compared with those in the non-acute kidney injury group $(\mathrm{p}<0.001)$

Conclusion: The neutrophil gelatinase-associated lipocalin may be used as an alternative biomarker to serum creatinine in differentiation of ischemic damage in patients undergoing laparoscopic partial nephrectomy.

Keywords: Acute kidney injury, laparoscopic partial nephrectomy, neutrophil gelatinase-associated lipocalin, reperfusion damage
Laparoscopic partial nephrectomy (LPN), which minimizes renal function loss due to its nephron sparing nature, has become a standard technique among many experienced centers worldwide for surgical treatment of localized kidney tumors (1). Renal artery clamping is used during partial nephrectomy to improve the visibility of the excised surgical field. However, resultant renal ischemia can cause damage to the kidney parenchyma. Several previous reports established that the duration of warm ischemia time (WIT) during cross clamping of renal artery is correlated with the magnitude of renal damage (2,3). Traditionally, WIT should be 20-25 minutes and

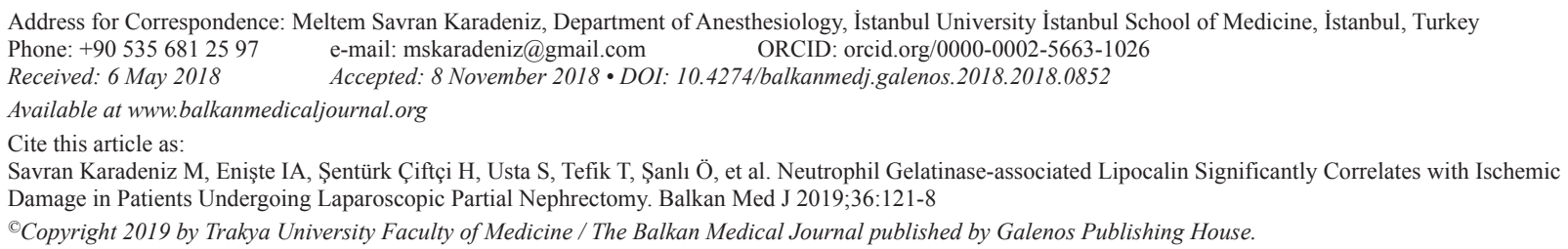


not exceed 30 minutes (4). Researchers have yet been questioning whether kidney functions are affected in the long-term due to the duration of warm ischemia. Recent studies have demonstrated that maintaining the quality and quantity of renal parenchyma during the surgery is more important in identifying long-term kidney outcomes than the duration of renal ischemia (5-7). In addition, the opposite kidney is more sensitive to ischemia in patients with two kidneys relative to patients with solitary kidneys (1). Several diseases, such as diabetes mellitus, hypertension, and coronary artery diseases, may contribute to the immensity of lost renal function after partial nephrectomy (4).

Acute kidney injury (AKI) is the deterioration of kidney functions within hours and is more directly associated with morbidity and mortality than expected in perioperative period. AKI, a significant risk factor for long-term chronic kidney dysfunction, is associated with the development of perioperative increased incidence of sepsis, anemia, coagulopathy, and extended mechanical ventilation and induces the occurrence of injuries in different organs (8-11). The diagnosis of kidney injury in the early period enables the development of various renoprotective strategies, such as extensive perioperative hemodynamic follow-up and proper fluid regimen regulation. Serum creatinine $(\mathrm{sCr})$ is a commonly used measure of kidney function. However, $\mathrm{sCr}$ may be misleading due to differences in age, sex, and body mass index among patients. The sCr levels increase as early as 24-48 hours after the development of kidney injury. In this regard, researchers have used other specific biomarkers for identification of kidney injury to make early diagnosis (12-14). Neutrophil gelatinase-associated (NGAL) is a significant biomarker that has diagnostic and prognostic significance in early diagnosis of kidney ischemia-reperfusion injury. We selected NGAL as biomarker in this study because of its high specificity and sensitivity in AKI (15).

In this study, we aimed to demonstrate the frequency of the development of AKI following LPN in patients with healthy contralateral kidney and determine the early predictive effects of serum NGAL levels on ischemia-reperfusion injury and its association with WIT. Our primary hypothesis is that serum NGAL levels would increase in patients with $\mathrm{AKI}$ at the postoperative $2^{\text {nd }}$ hour.

\section{MATERIALS AND METHODS}

This study sought the ethics committee approval and obtained written informed consent from the participants. Eighty patients classified with physical status I-III based on the American Society of Anesthesiologists, aged between 40 and 70 years, and scheduled for elective LPN were enrolled in this prospective cross-sectional study between September 2013 and February 2015. Patients were excluded if they had pre-existing renal insufficiency [estimated glomerular filtration rate (eGFR) $<60 \mathrm{~mL} / \mathrm{min} / 1.73$ ], congestive heart failure, and peripheral vascular disease and if they used nephrotoxic drugs, such as aminoglycosides, amphotericin, and ciclosporin.

\section{Anesthesia technique}

The preoperative preparations and anesthesia techniques were performed similarly among all patients. Routine monitorization was conducted using electrocardiogram, non-invasive blood pressure, and pulse oximetry $\left(\mathrm{SpO}_{2}\right)$. Subsequently, $5 \mathrm{~mL} / \mathrm{kg} / \mathrm{h}$ ringer lactate intravenous infusion was initiated. General anesthesia was induced using $0.03 \mathrm{mg} / \mathrm{kg}$ midazolam, $2 \mathrm{mg} / \mathrm{kg}$ propofol, $0.6 \mu \mathrm{g} /$ $\mathrm{kg}$ rocuronium, and $0.2 \mu \mathrm{g} / \mathrm{kg}$ remifentanil. Mechanical ventilation was achieved with tidal volume of $8 \mathrm{~mL} / \mathrm{kg}$, respiratory rate of $10-12 /$ minute, and positive end-expiratory pressure of $4 \mathrm{~cm}$ of $\mathrm{H}_{2} \mathrm{O}$ after the insertion of an endotracheal intubation tube. The patients were positioned at $45^{\circ}-60^{\circ}$ modified flank position with minimal elevation of the kidney bridge. Anesthesia was maintained with $4 \%-6 \%$ desflurane in a mixture of $40 \%$ oxygen and $60 \%$ air and $0.1 \mu \mathrm{g} / \mathrm{kg} / \mathrm{min}$ remifentanil infusion to maintain the intraoperative blood pressure within $20 \%$ of the preoperative values. Volume replacement and $5 \mathrm{mg}$ incremental ephedrine were administered to the patients in incidents of hypotension. Bradycardia (heart rate $<50$ beats $/ \mathrm{min}$ ) was treated using $0.01 \mathrm{mg} / \mathrm{kg}$ atropine. At the end of the surgery, the patients were extubated and transported to the postanesthesia care unit.

\section{Surgery technique}

The patients were placed on modified flank position for LPN. About $15 \mathrm{mmHg}$ pneumoperitoneum was created using a Veress needle. Following the insertion of three ports, the bowel was medially mobilized, the ureter was identified, and the renal artery was found. Gerota's fascia was dissected, and the resection site was scored with monopolar cautery. The tumor was resected on the previously scored margins by using cold scissors following the hilar renal artery clamping. Inner layer renorrhaphy was performed using unidirectional-barbed suture, and the outer layer was closed with sliding Hem-o-lok clip technique. Whenever needed, the defect was covered with oxidized cellulose (Surgicel, Ethicon Inc., Somerville, NJ, USA). The renal artery was unclamped following the completion of renorrhaphy, and the specimen was retrieved with a laparoscopic entrapment bag.

\section{Clinical outcomes}

We analyzed the demographic characteristics of patients, tumor size, operating time, duration of anesthesia, and WIT. Intraoperative hemodynamic data (heart rate and mean arterial pressure) were recorded. The levels of sCr, eGFR, and NGAL were evaluated before the surgery (preoperative), 2 hours after completion of the surgery (postoperative $2^{\text {nd }}$ hour), and on postoperative days 1 and 2. eGFRs were calculated using the "chronic kidney disease epidemiology" formula (16). Postoperative AKI was defined as an increase in the $\mathrm{sCr}$ level within the postoperative 48 hours by more than or equal to $50 \%$ from the baseline (17).

\section{Collection of serum samples}

Blood samples were obtained for measurement of $\mathrm{sCr}$, eGFR, and NGAL levels. The samples were collected preoperatively, at the postoperative $2^{\text {nd }}$ hour, and on postoperative days 1 and 2 . Peripheral venous blood samples were collected in vacutainers and allowed to clot for 30 minutes at room temperature prior to centrifugation at $1.600 \times \mathrm{g}$ for 10 minutes at room temperature. The samples were stored at $-80{ }^{\circ} \mathrm{C}$ until assay. 


\section{Determination of serum NGAL levels}

NGAL concentration was determined using an enzyme-linked immunosorbent assay kit (Biovendor-Laboratorni Medicina, Brno, Czech Republic). NGAL detection kits were labeled for research use and incorporated in assays based on sandwich enzyme-linked immunosorbent assay technology. Absorbance was recorded with a microtiter plate reader at $450 \mathrm{~nm}$. Each sample was tested in duplicate, and the coefficient of intraassay variation among the duplicates was $<10 \%$. NGAL concentration was calculated from the standard curves by linear regression analysis.

\section{Statistical analysis}

Statistical analysis was performed using the Statistical Package for the Social Sciences version 21.0. The creatinine level was $1.01 \pm 0.4 \mathrm{mg} /$ $\mathrm{dL}$ on postoperative day 2 in patients with $\mathrm{AKI}$ in our pilot study. A minimum of 70 patients would be required to obtain a 0.28 difference with a standard deviation of 0.4 , with $\alpha$ and $\beta$ errors of 0.05 and 0.2 , respectively. Therefore, 80 patients were selected in case of drop outs. eGFR was calculated by "chronic kidney disease epidemiology" formula. Kolmogorov-Smirnov test was performed to assess deviation from normal distribution. Quantitative variables were summarized as mean and standard deviation or as median. The different patient groups (AKI group vs non-AKI group) were compared using Student's t-test and Mann-Whitney $U$ test for quantitative variables and $\mathrm{X}^{2}$ test for categorical data. Differences among all parameters at different time points were assessed by repeated measures ANOVA for quantitative variables. Correlation analysis was performed using Spearman's test. Factors potentially influencing variations in NGAL level were evaluated in univariate analysis. The threshold value of NGAL level in accordance with AKI classification was investigated using receiver operating characteristic. Sensitivity, specificity, positive predictive level, negative predictive level, and accuracy rate were evaluated in accordance with the specified threshold levels. The significance value was regarded as $\mathrm{p}<0.05$.

\section{RESULTS}

Eighty patients who underwent LPN were included in the study. Five patients were excluded because their serum samples were not stored under the optimal conditions. The demographic and clinical characteristics of the 75 patients are shown in Table 1. The patients were divided into AKI and non-AKI groups. We did not observe any significant differences in demographic data between the two groups ( $\mathrm{p}>0.05)$. Baseline (preoperative), $\mathrm{sCr}$, eGFR, and NGAL levels were not significantly different between AKI and non-AKI groups $(\mathrm{p}>0.05)$ (Table 1$)$. No significant difference was also observed in mean arterial pressure values during the intraoperative and postoperative early period $(\mathrm{p}>0.05)$ (Figure $1)$. The $\mathrm{sCr}$ values were significantly higher and the eGFR values were significantly lower on postoperative days 1 and 2 compared with the preoperative values $(\mathrm{p}<0.001)$ (Table 2$)$. The NGAL levels were significantly higher at the postoperative $2^{\text {nd }}$ hour and on postoperative day 1 compared with the preoperative values $(\mathrm{p}<0.001)$ (Table 2). We analyzed the correlation among the variables measured. A significant correlation was found between WIT and NGAL levels at the postoperative $2^{\text {nd }}$ hour $(r=0.398$, $\mathrm{p}=0.003$ ) (Figure 2). However, this significance disappeared on postoperative day $1(\mathrm{r}=0.209, \mathrm{p}=0.081)$ (Figure 3$)$. Twenty-seven patients developed AKI on postoperative day 2. The NGAL levels increased significantly at the postoperative $2^{\text {nd }}$ hour in the AKI group compared with those in the non-AKI group $(\mathrm{p}=0.048)$. However, on postoperative day 1 , no significant difference was found between AKI and non-AKI groups ( $>0.05$ ) (Table 3 ). The $\mathrm{sCr}$ values were significantly higher and the eGFR values were significantly lower on postoperative days 1 and 2 in the

TABLE 1. Demographic characteristics of patients

\begin{tabular}{|c|c|c|c|c|}
\hline Parameters & $\begin{array}{c}\text { Patients } \\
(\mathrm{n}=75)\end{array}$ & $\begin{array}{c}\text { AKI group } \\
(\mathrm{n}=27) 36.0 \%\end{array}$ & $\begin{array}{c}\text { Non-AKI group }(\mathrm{n}=48) \\
64.0 \%\end{array}$ & $\mathrm{p}$ \\
\hline Female & $30(40 \%)$ & $10(13.3 \%)$ & $20(26.7 \%)$ & 0.694 \\
\hline Weight (kg) & $78.46 \pm 12.21$ & $77.70 \pm 12.26$ & $79.08 \pm 11.92$ & 0.635 \\
\hline ASA 1 & $26(34.7 \%)$ & $12(16.0 \%)$ & $14(18.7 \%)$ & 0.408 \\
\hline Tm size & $3.67 \pm 1.24$ & $3.52 \pm 1.45$ & $3.75 \pm 1.34$ & 0.481 \\
\hline Diabetes mellitus & $9(12.0 \%)$ & $4(5.3 \%)$ & $5(6.7 \%)$ & 0.714 \\
\hline Hypertension & $23(30.7 \%)$ & $12(16.0 \%)$ & $11(14.7 \%)$ & 0.069 \\
\hline Duration of anesthesia (minute) & $150.36 \pm 28.24$ & $150.53 \pm 29.14$ & $151.95 \pm 22.01$ & 0.644 \\
\hline Baseline NGAL (ng/mL) & $72.71 \pm 46.85$ & $84.72 \pm 47.45$ & $64.52 \pm 39.79$ & 0.053 \\
\hline
\end{tabular}

Data were mean \pm standard deviation or number (\%); ASA: American Society of Anesthesiology; AKI: acute kidney injury; eGFR: estimated glomerular filtration rate; n: number of individuals; NGAL: neutrophil gelatinase-associated lipocalin; sCr: serum creatinine 


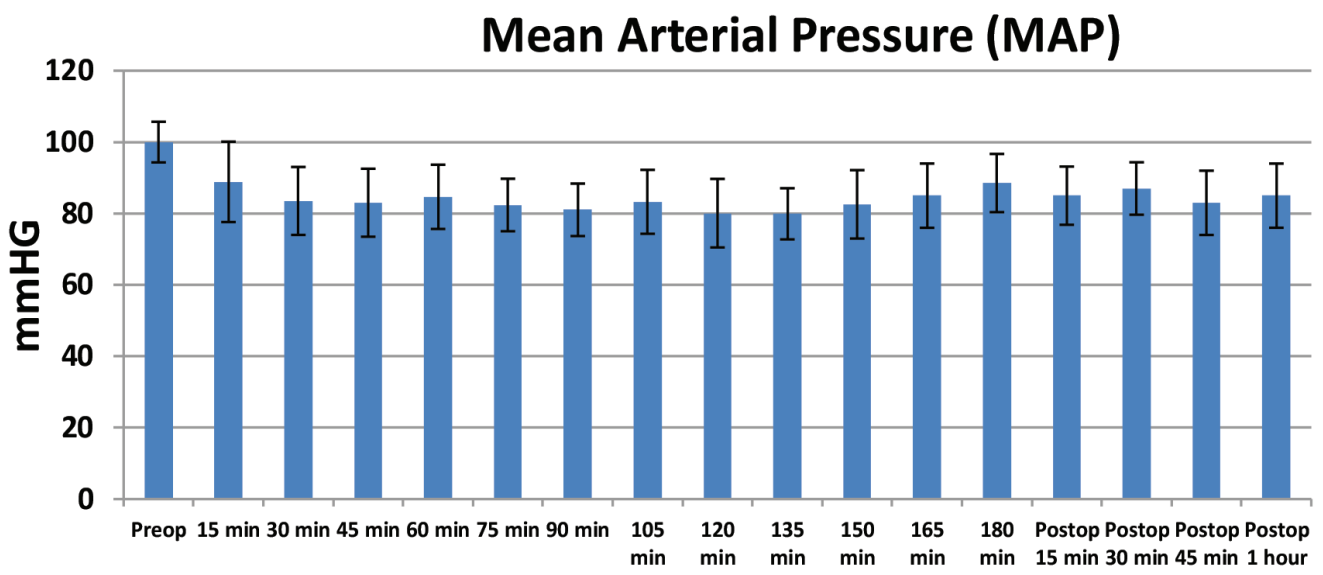

FIG. 1. Mean arterial pressure $(\mathrm{mmHg})$ follow-up throughout the perioperative period. Data are presented as mean \pm standard deviation.

TABLE 2. Levels of sCr, NGAL, and eGFR presented as mean \pm standard deviation

\begin{tabular}{|c|c|c|c|}
\hline Parameter & Time & Levels & $\mathrm{p}$ \\
\hline \multirow[t]{6}{*}{$\mathrm{sCr}(\mathrm{mg} / \mathrm{dL})$} & Preoperative & $0.91 \pm 0.16$ & \multirow{2}{*}{$<0.001^{*}$} \\
\hline & Postoperative day 1 & $1.08 \pm 0.32$ & \\
\hline & Preoperative & $0.91 \pm 0.16$ & \multirow{2}{*}{$<0.001^{*}$} \\
\hline & Postoperative day 2 & $1.19 \pm 0.41$ & \\
\hline & Postoperative day 1 & $1.08 \pm 0.32$ & \multirow{2}{*}{$<0.001^{*}$} \\
\hline & Postoperative day 2 & $1.19 \pm 0.41$ & \\
\hline \multirow[t]{6}{*}{ NGAL (ng/mL) } & Preoperative & $72.71 \pm 46.85$ & \multirow{2}{*}{$<0.001 *$} \\
\hline & Postoperative $2^{\text {nd }}$ hour & $131.93 \pm 87.39$ & \\
\hline & Preoperative & $72.71 \pm 46.85$ & \multirow{2}{*}{$<0.001 *$} \\
\hline & Postoperative day 1 & $189.64 \pm 104.52$ & \\
\hline & Postoperative $2^{\text {nd }}$ hour & $131.93 \pm 87.39$ & \multirow{2}{*}{$<0.001^{*}$} \\
\hline & Postoperative day 1 & $189.64 \pm 104.52$ & \\
\hline \multirow[t]{6}{*}{ eGFR (mL/min) } & Preoperative & $85.27 \pm 22.12$ & \multirow{2}{*}{$<0.001 *$} \\
\hline & Postoperative $2^{\text {nd }}$ hour & $73.68 \pm 21.42$ & \\
\hline & Preoperative & $85.27 \pm 22.12$ & \multirow{2}{*}{$<0.001 *$} \\
\hline & Postoperative day 1 & $66.15 \pm 19.91$ & \\
\hline & Postoperative $2^{\text {nd }}$ hour & $73.68 \pm 21.42$ & \multirow{2}{*}{$<0.001^{*}$} \\
\hline & Postoperative day 1 & $66.15 \pm 19.91$ & \\
\hline
\end{tabular}

*p value $<0.05$; eGFR: estimated glomerular filtration rate; n: number of individuals; NGAL: neutrophil gelatinase-associated lipocalin; sCr: serum creatinine

TABLE 3. NGAL presented as median (minimum-maximum) and $\mathrm{sCr}$ and eGFR presented as mean \pm standard deviation

\begin{tabular}{|c|c|c|c|c|}
\hline & & $\begin{array}{l}\text { AKI group } \\
(n=27)\end{array}$ & Non-AKI group $(n=48)$ & $\mathrm{p}$ \\
\hline \multirow[t]{3}{*}{ Serum NGAL (ng/mL) } & Preoperative & $68.5(19.7-170.0)$ & $59.1(19.2-229.5)$ & 0.053 \\
\hline & Postoperative $2^{\text {nd }}$ hour & $158.5(63.4-350.4)$ & $120.6(46.1-350.0)$ & $0.048 *$ \\
\hline & Postoperative day 1 & $234.3(62.3-414.5)$ & $149.7(63.1-366.2)$ & 0.054 \\
\hline \multirow[t]{3}{*}{$\mathrm{sCr}(\mathrm{mg} / \mathrm{dL})$} & Preoperative & $0.91 \pm 0.19$ & $0.92 \pm 0.15$ & 0.845 \\
\hline & Postoperative day 1 & $1.31 \pm 0.37$ & $0.95 \pm 0.19$ & $<0.001 *$ \\
\hline & Postoperative day 2 & $1.49 \pm 0.50$ & $1.01 \pm 0.18$ & $<0.001 *$ \\
\hline \multirow[t]{3}{*}{ eGFR (mL/min) } & Preoperative & $83.83 \pm 18.01$ & $87.81 \pm 28.17$ & 0.458 \\
\hline & Postoperative day 1 & $58.93 \pm 18.63$ & $81.98 \pm 18.30$ & $<0.001^{*}$ \\
\hline & Postoperative day 2 & $49.67 \pm 12.10$ & $75.42 \pm 17.31$ & $<0.001^{*}$ \\
\hline
\end{tabular}


AKI group compared with those in the non-AKI group $(\mathrm{p}<0.001)$ (Table 3). Twenty-four patients had NGAL levels above the calculated cut-off value despite having normal $\mathrm{sCr}$ levels on postoperative day 1 .

We determined the sensitivities, specificities, and positive and negative predictive values for NGAL at different cut-off levels for the postoperative $2^{\text {nd }}$ hour and on postoperative day 1 (Tables 4 , 5). Figure 4 shows the receiver operating characteristic curve for the postoperative NGAL levels. The area under the curve could be explained as follows.

The area under the curve was 0.627 [confidence interval (CI): 0.494-0.759, $\mathrm{p}=0.042]$; at a cut-off value of $129.375 \mathrm{ng} / \mathrm{mL}$ NGAL at the postoperative $2^{\text {nd }}$ hour, the sensitivity and specificity were $70.0 \%$ and $68.3 \%$, respectively. The receiver operating characteristic curve analysis confirmed the positive value of NGAL for predicting AKI $(46.5 \%)$ at the postoperative $2^{\text {nd }}$ hour (Table 4$)$. The area under the curve was 0.623 (CI: 0.489-0.758, $\mathrm{p}=0.048$ ); and at a cut-off value of $184.300 \mathrm{ng} / \mathrm{mL} \mathrm{NGAL}$ on day 1 , the sensitivity and specificity were $73.3 \%$ and $63.3 \%$, respectively.
The receiver operating characteristic curve analysis confirmed the positive value of NGAL for prediction of AKI (53.3\%) on postoperative day 1 (Table 5).

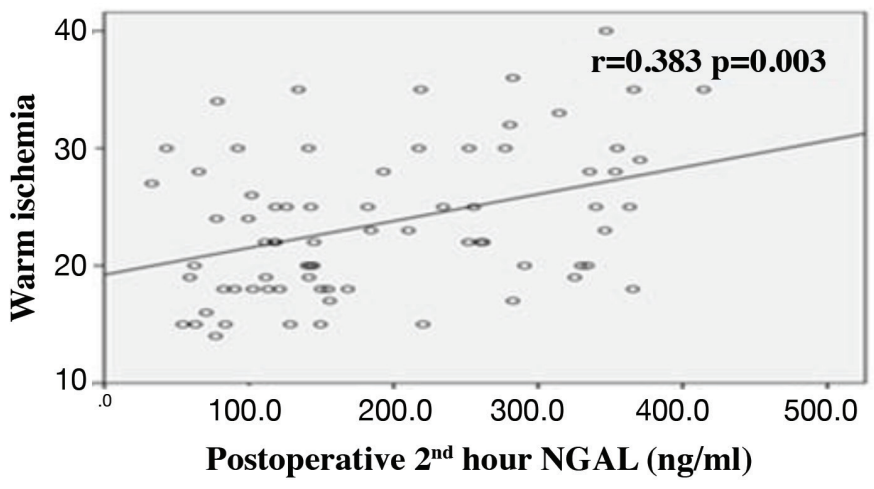

FIG. 2. Correlation of warm ischemia time and NGAL levels at postoperative $2^{\text {nd }}$ hour. NGAL: neutrophil gelatinase-associated lipocalin

TABLE 4. Sensitivity, specificity, and positive and negative predictive values of NGAL levels at the postoperative $2^{\text {nd }}$ hour in patients who developed AKI

\begin{tabular}{|c|c|c|c|c|c|}
\hline & & \multicolumn{2}{|c|}{ AUC 95\% CI } & $\mathrm{p}$ & Cut-off \\
\hline \multicolumn{2}{|l|}{ NGAL postoperative $2^{\text {nd }}$ hour (ng/mL) } & \multicolumn{2}{|c|}{$0.627(0.494-0.759)$} & 0.042 & 129.375 \\
\hline & & \multicolumn{2}{|c|}{ AKI score } & Kappa value & $\mathrm{p}$ \\
\hline & & Negative & Positive & & \\
\hline \multirow[t]{4}{*}{ NGAL postoperative $2^{\text {nd }}$ hour (ng/mL) } & Negative & $35(72.9)$ & $9(33.3)$ & 0.124 & 0.202 \\
\hline & Positive & $13(27.1)$ & $18(66.7)$ & & \\
\hline & Total & 48 & 27 & & \\
\hline & & & & & $95 \% \mathrm{CI}$ \\
\hline Sensitivity & & & 70.0 & & $32.3-83.7$ \\
\hline Specificity & & & 68.3 & & 44.9-70.9 \\
\hline PPV & & & 46.5 & & $17.8-57.5$ \\
\hline NPV & & & 85.4 & & $75.2-91.8$ \\
\hline
\end{tabular}

TABLE 5. Sensitivity, specificity, and positive and negative predictive values of NGAL levels on postoperative day 1 in patients who developed AKI

\begin{tabular}{|c|c|c|c|c|c|}
\hline & & \multicolumn{2}{|c|}{ AUC 95\% CI } & $\mathrm{p}$ & Cut-off \\
\hline \multicolumn{2}{|l|}{ NGAL postoperative day $1(\mathrm{ng} / \mathrm{mL})$} & \multicolumn{2}{|c|}{$0.623(0.489-0.758)$} & 0.048 & 184.300 \\
\hline & & \multicolumn{2}{|c|}{ AKI score } & Kappa value & $\mathrm{p}$ \\
\hline & & Negative & Positive & & \\
\hline \multirow[t]{4}{*}{ NGAL postoperative day $1(\mathrm{ng} / \mathrm{mL})$} & Negative & $27(56.2)$ & $10(37.0)$ & 0.253 & 0.011 \\
\hline & Positive & $21(43.8)$ & $17(63.0)$ & & \\
\hline & Total & 48 & 27 & & \\
\hline & & & & & $95 \% \mathrm{CI}$ \\
\hline Sensitivity & & & 73.3 & & $44.9-92.2$ \\
\hline Specificity & & & 63.3 & & $49.9-75.4$ \\
\hline PPV & & & 53.3 & & $24.2-63.9$ \\
\hline NPV & & & 90.5 & & $80.1-95.7$ \\
\hline
\end{tabular}




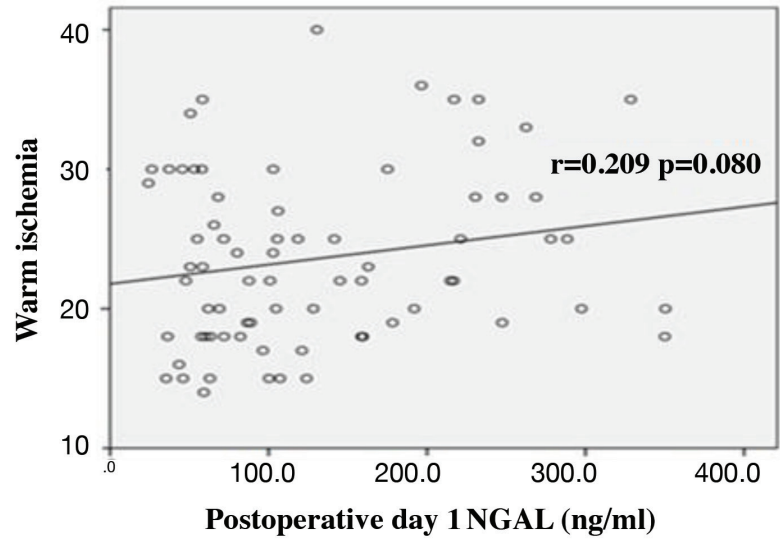

FIG. 3. Correlation of warm ischemia time and NGAL levels at postoperative day 1 . NGAL: neutrophil gelatinase-associated lipocalin

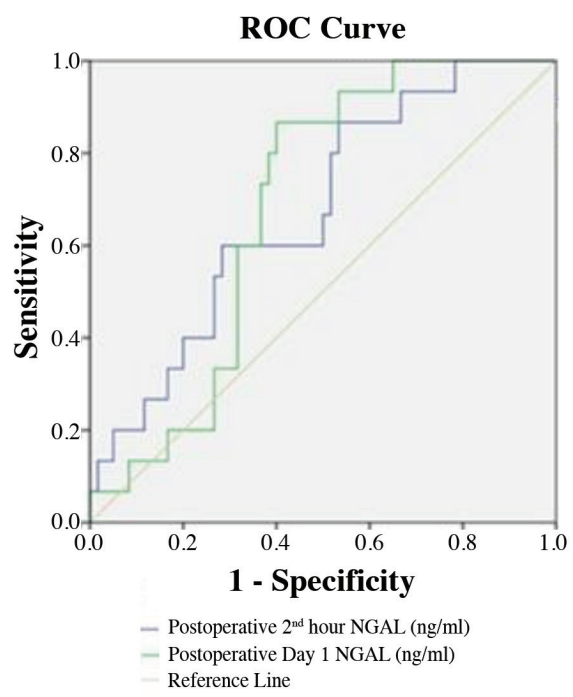

FIG. 4. ROC curve of NGAL. Sensitivity, specificity, positive and negative predictivity of NGAL levels at postoperative $2^{\text {nd }}$ hour and on postoperative day 1 in patients who developed AKI.

NGAL: neutrophil gelatinase-associated lipocalin; ROC: receiver-operating characteristic; AKI: acute kidney injury

\section{DISCUSSION}

In this prospective clinical study, we observed that the serum NGAL levels significantly increased at the postoperative $2^{\text {nd }}$ hour in patients with AKI compared with those in patients without AKI. A positive correlation was detected between WIT and serum NGAL levels at the postoperative $2^{\text {nd }}$ hour. In addition, the $\mathrm{sCr}$ and NGAL levels were significantly higher in the postoperative period than in the preoperative period. We suggested that the rate of postoperative development of AKI might be higher than the estimated rate in such cases and that NGAL could a significant biomarker in early diagnosis of kidney damage.

In partial nephrectomy, the primary goal is to control cancer while preserving the maximal renal function and obtaining minimal morbidity in the perioperative period. We found a decrease in kidney functions by about $20 \%$ in solitary operated kidney and by $10 \%$ in global function in partial nephrectomies. Progressive chronic kidney failure may also develop in acute period in addition to severe kidney damage that required dialysis in $1 \%$ of patients (18).

The development of severe AKI is associated with conditions, such as the need for intensive care and dialysis, which increases hospital stay (10). The most significant factor in preservation of kidney function in minimal invasive nephrectomies is the preservation of the nephron mass. Tumor size, loss of normal parenchyma during tumor resection, deterioration of blood flow, and blood saturation cause renal function loss in the postoperative period $(19,20)$. Mir et al. (21) reported a significant decrease in the eGFR value after the resection of huge tumors. Another study on patients with solitary kidney reported that a $15 \%$ loss of parenchyma caused deterioration of renal function by $19.7 \%$ postoperatively (22). Whether WIT promotes kidney function deterioration remains controversial. In their first study, Thompson et al. $(23,24)$ reported that increased ischemia time caused a decrease in kidney functions. However, in the proceeding follow-up of the same patient group, they reported that WIT had no predictive value in the diagnosis when predicting for long-term renal dysfunction. After the correlative analyses of biomarkers and histologic evaluations, different authors reported that minimal structural and functional changes might develop during the WIT of 15-60 minutes, which would not result in irreversible changes in kidneys (11). In our study, the mean tumor size was $3.6 \mathrm{~cm}$, and the mean WIT was 24 minutes. This period is within the reasonable limits as mentioned in the above studies. In addition, the NGAL increase at the postoperative $2^{\text {nd }}$ hour was positively correlated with WIT.

Hemodynamic changes, particularly mean arterial pressure, in the intraoperative period have a significant role in kidney perfusion. Even the short-period hypotension attacks in this period may cause ischemia in the kidney. Walsh et al. (25) reported the correlation of mean arterial pressure (mean arterial pressure $<55 \mathrm{mmHg}$ ) with the development of AKI in a wide patient population of non-cardiac surgery group. Mean arterial pressure $<60 \mathrm{mmHg}$ for over 20 minutes or mean arterial pressure $<55 \mathrm{mmHg}$ for over 10 minutes was associated with high AKI risk (26). No hypotension attack unresponsive to fluid and ephedrine treatment was observed in the intraoperative period in our study. We detected no differences in the periodic measurements during the surgery. Hemodynamic stability is as important as the other factors in influencing ischemia risk after partial nephrectomy.

Energy stocks are wasted due to decrease in enabling oxygen to the tissues after ischemia because of various causes in the kidney; this phenomenon results in cell necrosis and accumulation of toxic metabolites. The products developed after the reperfusion of ischemic tissue activate the mast cells and neutrophils; the local cell damage causes systemic inflammatory reaction and secretion of cytokine and inflammatory mediators that cause multi organ failure (27). Therefore, early diagnosis of AKI, proper monitorization, and initiation of protective treatments are significant measures for prevention of permanent kidney damage. $\mathrm{sCr}$ and accompanying eGFR changes in diagnosis of AKI may frequently be missed out particularly when the opposite kidney is healthy (1) and thus could not predict the initial time of damage neither the degree of severity. $\mathrm{sCr}$ starts to increase when the kidney function decreases by $50 \%$ 
and varies in accordance with individual factors, such as muscle mass, sex, exercise, and diet. Thus, researchers have explored specific and sensitive new biomarkers to diagnose ischemia in recent years.

NGAL, a member of the lipocalin family, is secreted from kidney proximal tubuli after ischemic damage. Ischemia causes an increase in the urine and serum levels of NGAL. However, NGAL was not routinely used in the clinics but has been employed in cardiovascular surgery, intensive care, and transplant surgery; NGAL increased within 2 hours immediately after the development of damage $(28,29)$. Woodson et al. (12) created warm ischemia for 15,30 , and 60 minutes in rats with a single kidney and demonstrated that the urine NGAL level increased to the maximum level within 30 minutes of renal artery clamping. In the present study, we used serum NGAL value. As indicated by Sprenkle, monitoring the NGAL increase in serum may be less misleading because the increase in the production in ischemic kidney in partial nephrectomies of healthy patients with two functional kidneys might be diluted if the opposite kidney produces a high volume of urine (13).

To date, few clinical studies have demonstrated the importance of NGAL in diagnosis of possible AKI in partial nephrectomies. However, Abbasi et al. (30) reported an increase in the urine NGAL levels at the $1^{\text {st }}$ hour following the cold ischemia in nephron sparing open partial nephrectomies of a small number of patients. Sprenkle found no significant increase in the NGAL levels in the urine after open partial nephrectomy in individuals with healthy kidney functions and did not accept NGAL as a diagnostic factor. The detection of less damage in their study might be due to several factors, such as performing cold ischemia, which has a better kidney protection effect, in most patients during the renal artery clamping, and infusion of intraoperative mannitol (13).

We conducted tumor resection using laparoscopic method and under the warm ischemia in all patients. Pneumoperitoneum during laparoscopy increases the intraabdominal pressure, which might contribute to the deterioration of kidney perfusion. Similar to our study, the results of the study of Koo et al. (31) showed increased NGAL levels in the urine at the early postoperative period after LPN in patients with healthy contralateral kidney. However, they reported that the increased urine NGAL had no predictive value in the determination of the severity of AKI and in the diagnosis of longterm renal dysfunction.

In this study, the diagnostic value of serum NGAL level was measured using the receiver operating characteristic curve. The receiver operating characteristic curve analysis showed that serum NGAL level has a valuable diagnostic performance. As evidenced by the area under the curve of 0.67 , the biomarker NGAL has a good ability to predict AKI in the first 2 hours after partial nephrectomy. In our study, the serum NGAL level was significantly higher at the $2^{\text {nd }}$ hour compared with the preoperative values. The postoperative $\mathrm{sCr}$ level was also significantly higher compared with the preoperative values. In addition, AKI developed in $36 \%$ of the patients on day 2 , and their NGAL levels in the early period were significantly higher. Due to the lack of information about long-term patient follow-up, the rate of permanent renal damage is difficult to predict. This aspect can be regarded as a limitation of our study.
In conclusion, this study showed that increased serum NGAL levels at the $2^{\text {nd }}$ hour post LPN are predictive of increased risk of AKI. Early diagnosis of renal injury may prevent the side effects of this undesirable condition. Despite that it is more expensive than $\mathrm{sCr}$, NGAL is an alternative biomarker of AKI in the early postoperative period especially in patients with long WIT.

Conflict of Interest: No conflict of interest was declared by the authors.

Financial Disclosure: Our study was financed by the Scientific Research Projects Coordination Unit of İstanbul University (BAP/BYP-26020).

\section{REFERENCES}

1. Volpe A, Blute ML, Ficarra V, Gill IS, Kutikov A, Porpiglia F, et al. Renal Ischemia and Function After Partial Nephrectomy: A Collaborative Review of The Literature. Eur Urol 2015;68:61-74.

2. Choi JD, Park JW, Lee SY, Jeong BC, Jeon SS, Lee HM, et al. Does prolonged warm ischemia after partial nephrectomy under pneumoperitoneum cause irreversible damage to the affected kidney? J Urol 2012;187:802-6.

3. Funahashi Y, Hattori R, Yamamoto T, Kamihira O, Kato K, Gotoh M. Ischemic renal damage after nephron-sparing surgery in patients with normal contralateral kidney. Eur Urol 2009;55:209-15.

4. Lane BR, Gill IS, Fergany AF, Larson BT, Campbell SC. Limited warm ischemia during elective partial nephrectomy has only a marginal impact on renal functional outcomes. J Urol 2011;185:1598-603.

5. Parekh DJ, Weinberg JM, Ercole B, Torkko KC, Hilton W, Bennett M. et al. Tolerance of the human kidney to isolated controlled ischemia. J am Soc Nephrol 2013;24:506-17.

6. Simmons MN, Fergany AF, Champbell SC. Effect of parenchymal volume preservation on kidney function after partial nephrectomy. J Urol 2011;186:405-10.

7. Kallingal GJ, Weinberg JM, Reis IM, Nehra A, Venkatachalam MA, Parekh DJ. Longterm response to renal ischaemia in the human kidney after partial nephrectomy: results from a prospective clinical trial. BJU Int 2016;117:766-74.

8. Goren O, Matot I. Perioperative acute kidney injury. Br J Anaesth 2015;115(Suppl 2):3-14.

9. Cho A, Lee JE, Kwon GY, Huh W, Lee HM, Kim DJ, et al. Post-operative acute kidney injury in patients with renal cell carcinoma is a potent risk factor for newonset chronic kidney disease after radical nephrectomy. Nephrol Dial Transplant 2011;26:3496-501.

10. Loef BG, Henning RH, Navis G, Rankin AJ, van Oeveren W, Ebels T, et al. Changes in glomerular filtration rate after cardiac surgery with cardiopulmonary bypass in patients with mild preoperative renal dysfunction. Br J Anaesth 2008;100:759-64.

11. Mir MC, Pavan N, Parekh DJ. Current Paradigm for Ischemia in Kidney Surgery. J Urol 2016;195:1655-63.

12. Woodson BW, Wang L, Mandava S, Lee BR. Urinary Cystatin C and NGAL as early biomarkers for assesment of renal ischemia-reperfusion injury: A serum marker to replace creatinine? J Endourol 2013;27:1510-5.

13. Sprenkle PC, Wren C, Maschino AC, Feifer A, Power N, Ghoneim T, et al. Urine neutrophil gelatinase-associated lipocalin as a marker of acute kidney injury after kidney surgery. J Urol 2013;190:159-64.

14. Kim Y, Cho YS, Kym D, Yoon J, Yim H, Hur J, et al. Diagnostic performance of plasma and urine neutrophil gelatinase-associated lipocalin, cystatin $\mathrm{C}$, and creatinine for acute kidney injury in burn patients: A prospective cohort study. PLoS One 2018;13:e199600.

15. Kim H, Hur M, Cruz DN, Moon HW, Yun YM. Plasma neutrophil gelatinaseassociated lipocalin as a biomarker for acute kidney injury in critically ill patients with suspected sepsis. Clin Biochem 2013;46:1414-8.

16. Levey AS, Stevens LA, Schmid CH, Zhang YL, Castro AF, Feldman HI, et al. A new equation to estimate glomerular filtration rate. Ann Intern Med 2009;150:604-12.

17. Mehta LR, Kellum JA, Shah SV, Molitoris BA, Ronco C, Warnock DG, et al. Acute Kidney Injury Network. Acute Kidney Injury Network: report of an initiative to improve outcomes in acute kidney injury. Crit Care 2007;11:31.

18. Hilyer SP, Bahayani SB, Allaf ME, Rogers CG, Stifelman MD, Tanagho Y, et al. Robotic partial nephrectomy for solitary kidney: a multi-instutional analysis. Urology 2013;81:93-7. 
19. Bagheri F, Pusztai C, Farkas L, Kallidonis P, Buzogány I, Szabó Z, al. Impact of parenchymal loss on renal function after laparoscopic partial nephrectomy under warm ischemia. World J Urol 2016;34:1629-34.

20. Song C, Park S, Jeong IG, Hong JH, Park HK, Kim CS, et al. Follow up of unilateral renal function after laparoscopic partial nephrectomy. J Urol 2011;186;53-8

21. Mir MC, Ercole C, Takagi T, Zhang Z, Velet L, Remer EM, et al. Decline in renal function after partial nephrectomy: etiology and prevention. J Urol 2015;193:1889-98

22. Sharma N, O'Hara J, Novick AC, Lieber M, Remer EM, Herts BR, et al. Correlation between loss of renal function and loss of renal volume after partial nephrectomy for tumor in a solitary kidney. J Urol 2008; 179:1284-8.

23. Thompson RH, Lane BR, Lohse CM, Leibovich BC, Fergany A, Frank I, et al. Every minute counts when the renal hilum is clamped during partial nephrectomy. Eur Urol 2010;58:340-5

24. Thompson RH, Lane BR, Lohse CM, Leibovich BC, Fergany A, Frank I, et al. Renal function after partial nephrectomy: effect of warm ischemia relative to quantity and quality of preserved kidney. Urology 2012;79:356-60.

25. Walsh M, Devereaux PJ, Garg AX, Kurz A, Turan A, Rodseth RN, et al. Relationship between intraoperative mean arterial pressure and clinical outcomes after non cardiac surgery: toward an empirical definition of hypotension. Anesthesiology 2013;119:507-15
26. Sun LY, Wijeysundera DN, Tait GA, Beattie WS. Association of intraoperative hypotension with acute kidney injury after elective noncardiac surgery. Anesthesiology 2015; 123:515-23

27. Bonventre JV, Yang L. Cellular pathophysiology of ischemic acute kidney injury. J Clin Invest 2011;121:4210-21.

28. Shemin D, Dworkin LD. Neutrophil gelatinase-associated lipocalin (NGAL) as a biomarker for early acute kidney injury. Crit Care Clin 2011;27:379-89.

29. Mishra J, Dent C, Tarabishi R, Mitsnefes MM, Ma Q, Kelly C, et al. Neutrophil gelatinase- associated lipocalin (NGAL) as a biomarker for acute renal injury after cardiac surgery. Lancet 2005;365:1231-8.

30. Abbasi Z, Shalabi A, Sohotnik R, Nativ O, Awad H, Bishara B. et al. Urinary NGAL and KIM-1: biomarkers for assessment of acute ischemic kidney injury following nephron sparing surgery. J Urol 2013;189:1559-66.

31. Koo CK, Hong HJ, Lee SH, Jeh SU, Choi YD, Rha KH. et al. Accuracy of urinary neutrofil gelatinase-associated lipocalin in quantifying acute kidney injury after partial nephrectomy in patients with normal contralateral kidney. PlosOne 2015;22:1-11 